\title{
Evolução e distribuição do emprego formal no setor público brasileiro - 1996 a 2012
}

Gilson Geraldino Silva Jr*

Resumo: Este artigo analisa a evolução do emprego formal no Brasil no setor público ao longo de 16 anos e sua distribuição por natureza jurídica, região e escolaridade a partir de microdados da Rais trabalhador. Dos resultados que encontramos ressaltamos i) o aumento sistemático do emprego no executivo municipal, que passa de $26 \%$ da totalidade de servidores públicos formalmente empregados em 1996 para 43\% em 2012, muito provavelmente refletindo o aumento do número de municípios e as maiores responsabilidades municipais oriundas na Constituição de 1988, ii) a drástica queda da escolaridade baixa, de 34\% em 1996 para 9\% em 2012, substancial aumento da escolaridade alta, que passa de $21 \%$ em 1996 para 44\% em 2012, e certa estabilidade da escolaridade média, entre $45 \%$ e $50 \%$, e iii) no âmbito regional, leve perda de participação do sudeste e sul e suave aumento das outras regiões. Estes fenônemos mais gerais refletem, cremos, as mundanças instituicionais do Estado brasileiro desde a Carta de 1988, em particular descentralização e modernização - que exige servidores mais qualificados.

Palavras Chaves: mercado de trabalho, emprego formal, setor público.

Classificação JEL: J21; J45; J82.

\footnotetext{
* Bacharel e Mestre em Economia (UFMG) e Doutor em Economia (UFRGS). E-mail: gilsongsj@gmail.com 


\section{Contexto deste Estudo}

Osetor público tem peculiaridades e limites, mas ainda assiméimportante fonte de emprego. Estudos para outros países mostram que as característiscas dos mercados de trabalho público e privado são bem distintas, como concluiram Ehrenberg e Schwartz (1986), ao analisarem o mercado de trabalho no setor público americano. A principal distinção seria o objetivo dos agentes em cada um dos mercados: maximização de lucro não é a principal motivação no mercado de trabalho no setor público, mas é considerada a mais importante para os agentes no setor privado. De fato, os objetivos de burocratas e políticos diferem dos objetivos de proprietários e gerentes de empresas privadas. No setor público as decisões são tomadas em um ambiente político, enquanto que no setor privado as decisões são tomadas em um ambiente de mercado. Em suma, a natureza única dos agentes no mercado de trabalho no setor público (organizações não lucrativas), o arranjo institucional neste mercado, e as escolhas públicas que os direciona motivam estudar este mercado com atenção.

No caso brasileiro, o Estado passa por reformulações substanciais desde a Constituição de Federal de 1988, que entre várias mudanças, facilitou a criação de municipios e deu-lhes mais autonomia, como bem ilustra a extensa lista de competências constitucionais deste ente federado; e ampliou significativamente os chamados "direitos sociais", numa tentativa de universalizar entre os brasileiros conquistas obtidas em outros países que adotaram políticas de "bem estar social”, que já se encontram em sua terceira geração (Lavinas, 2013). Como consequências, mais municipios e pressão fiscal sobre os orçamentos de todos os membros da federação.

Uma extensa análise dos desdobramentos sócio-econômicos após 20 anos de promulgação da atual Carta Constitucional foi feita por Ipea (2009) em coletânea de artigos distribuídos em três volumes que abordaram i) seguridade e previdência social, saúde, assitência social e segurança alimentar, ii) educação, regulação das relações de trabalho, desenvolvimento agrário e cultura, e iii) justiça, direitos humanos, segurança pública, igualdade de gênero e racial. Em apertada síntese, pode-se concluir que houve avanços substanciais nos temas abordados, mas não suficientes para alçar o país aos patamares dos mais desenvolvidos. Beluzzo, Anuatti-Neto e Pazello (2005) analizaram a distribuição de salários e diferencias público-privado no Brasil, aspecto importante do mercado de tabalho. Utilizando dados da PNAD de 1995 e de 2001 encontraram que o diferencial a favor do setor público é maior na cauda inferior da distribuição de salários, declinando constantemente à medida em que nos deslocamos em direção à cauda superior.

Neste contexto de mudanças institucionais e seus efeitos de longo prazo, este artigo analisa o avanço do emprego ligado ao Estado entre 1996 e 2012 na dimensão temporal e por alguns recortes, como escolaridade, região e natureza jurídica dos estabelecimentos - que permite distinguir executivo, legislativo e judiciário, empresas, autarquias e fundações, nos âmbitos federal, estadual e municipal. Tal analise, até onde sabemos, ainda não foi feita. 
A seguir apresentamos a base de dados, onde descrevemos como as informações foram construídas e sintetizadas, com destaque para os filtros; os resultados e as interpretações; e as conclusões.

\section{Base de Dados e Variáveis}

A Relação Anual de Informações Sociais (RAIS) é um registro administrativo que deve ser obrigatoriamente preenchido e encaminhado ao Ministério do Trabalho e Emprego (MTE) por todo estabelecimento em território brasileiro formalmente constituído. Logo, a RAIS tem como unidade básica de obtenção de dados o estabelecimento. Estes dados são coletados no primeiro trimestre de cada ano, referindo-se ao ano anterior, e servem de base para os cálculos referentes ao pagamento do Abono Salarial.

A princípio, a RAIS cobriria todos os estabelecimentos existentes no país, não havendo, a priori, limite no número de vínculo empregatício. Porém, uma parte significativa dos estabelecimentos reporta ter nenhum vínculo empregatício ao longo do ano. Como as informações requeridas pela RAIS permitem observar o cumprimento da legislação trabalhista, há tendência de não declaração da Relação pelos estabelecimentos que não cumprem a legislação. Pela mesma razão, é possível que empresas informem menos vínculos que efetivamente têm, provavelmente porque o número de empregados contratados, respeitando as regras, é menor que o número de pessoas efetivamente empregadas pelo estabelecimento. Ainda assim, a RAIS pode ser considerada um censo do mercado de trabalho formal.

A RAIS existe desde 1976, mas somente na década de 90 sua cobertura passou a ser considerada confiável. Estima-se que, a partir desse período, cerca de $90 \%$ dos estabelecimentos formais existentes no país passaram a preencher esse registro administrativo regularmente.

Esta análise emprega dados da RAIS ${ }^{1}$ de 1996 a 2012. A partir da base de trabalhadores, constrói-se a base de dados de estabelecimentos, computando o estoque de vínculos ativos em 31/12 de cada ano.

Uma vez elaborada a base de estabelecimentos, alguns filtros de controle são aplicados. Basicamente, foram retirados os estabelecimentos que declararam ter nenhum funcionário e os que entregaram RAIS de forma intermitente: o fizeram em 1995, mas não em 1996, e o fizeram em 1997; o fizeram em 1995, mas não em 1996 e 1997, e o fizeram em 1998; e assim para todas as combinações de intermitência. Os estabelecimentos que aparecem somente em um ano, porém, foram mantidos. Isto feito, construímos as seguintes variáveis:

- $n_{i t}$ - número de trabalhadores do estabelecimento $i$ no ano $t$ (vínculos em 31/12).

- $S_{i t}$ - escolaridade do trabalhador

- $U F_{i t}$ - unidade da federação onde se localiza o estabelecimento.

- NatJurit - natureza jurídica do estabelecimento público

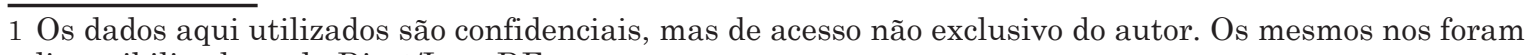
disponibilizados pela Diset/Ipea-DF. 
Com o objetivo de sintetizar as informações agrupamos algumas das variáveis. As categorias de escolaridade foram agrupadas em baixa (analfabetos, $4^{\mathrm{a}}$ série incompleta, $4^{\mathrm{a}}$ série completa e $8^{\mathrm{a}}$ série incompleta), média ( $8^{\mathrm{a}}$ série completa, segundo grau incompleto, segundo grau completo) e alta (superior incompleto e superior completo). As unidades da federação foram agrupadas em suas respectivas regiões.

A natureza jurídica dos estabelecimentos públicos permite distinguir se o estabelecimento é federal, estadual ou municipal, se pertence ao executivo, legislativo ou judiciário, ou se está entre outra categoria como autarquias e sociedades anônimas das quais o governo é sócio. Utilizamos aqui Executivo Federal, Executivo Estadual, Executivo Municipal, Legislativo Federal, Legislativo Estadual, Legislativo Municipal, Judiciario Federal, Judiciario Estadual, Autarquia Federal, Autarquia Estadual, Autarquia Municipal, Fundação Federal, Fundação Estadual, Fundação Municipal, Empresa Publica e Sociedade Anônima de Capital Aberto com Controle Acionário Estatal, doravante apenas Sociedade Anônima. Naturezas jurídicas associadas ao setor público que não se enquadram nas categorias descritas, como Órgão Público Autônomo, Comissão Polinacional, Fundo Público e Associação Pública, foram incorporadas na categoria "outros".

\section{Resultados e Interpretações}

As 10 Tabelas do anexo apresentam os resultados das tabulações feitas a partir da Rais trabalhador com os filtros acima. A Tabela 1 apresenta o número total de servidores públicos de nossa amostra. Percebemos que há aumento sistemático em relação ao ano anterior a partir de 1999, quando sai do patamar de 7,3 milhões para 11,7 milhões em 2012. Esta totalidade está assim distribuída por escolaridade (Tabela 2): 17,95\% baixa, 47,26\% média e 34,80\% alta. Por região (Tabela 3), $6,26 \%$ no norte, $21,15 \%$ no nordeste, $46,58 \%$ no sudeste, $14,86 \%$ no sul e $11,15 \%$ no centro oeste. E por natureza jurídica (Tabela $4)$, os executivos municipais $(38,3 \%)$ e estaduais $(26,19 \%)$ se destacam, sendo a participação do executivo federal de apenas $4,4 \%$. Os 3 poderes legislativos menos de $1 \%$ cada, e o judiciário federal e estadual com menos de $1,5 \%$ cada. Empresas públicas com 3,43\%, Sociedades Anônimas com 4,75\%, Fundações e Autarquias menos de $2 \%$ cada.

A natureza jurídica permite recortar a distribuição do emprego pelas características intrísecas do setor público, logo merece mais atenção. Observando a distribuição de servidores públicos por natureza jurídica e escolaridade (Tabela 5) percebemos que a escolaridade alta predomina no judiciário federal (72\%) e autarquias federais (61\%). Nas outras categorias prevalecem escolaridade média. Escolaridade baixa tem participação mais expressiva, acima de 20\%, somente no executivo municipal (24\%), autarquia municipal (29\%) e empresas públicas (23\%). 
Considerando a distribuição de servidores públicos por região e natureza jurídica (Tabela 6, que deve ser lida nas colunas), percebemos que cerca de 51\% do emprego público no nordeste está no executivo municipal. Já o executivo federal é responsável por $21 \%$ do emprego público no centro oeste, certamente devido ao Distrito Federal. O executivo estadual tem participações que variam entre $21 \%$ e $33 \%$. Já as outras categorias têm participação pouco expressiva, via de regra abaixo de $3 \%$ cada. Observando a distribuição de servidores públicos por natureza jurídica e região (Tabela 7 , que deve ser lida nas linhas), constatamos que $31 \%$ de todo emprego no legislativo estadual está na região norte e $27 \%$ do emprego nas fundações federais estão na região centro oeste. Já o emprego público no judiciário estadual, nas autarquias estaduais e municipais, nas empresas públicas e nas sociedades anônimas estão, na sua maioria (acima de 50\%) na região sudeste.

Por fim, vale observar a evolução do contingente de servidores públicos ao longo do tempo. A Tabela 8 apresenta proporções por natureza jurídica ao longo dos anos. Algumas tendências chamam a atenção: i) o aumento sistemático do emprego no executivo municipal, que passa de $26 \%$ da totalidade de servidores públicos formalmente empregados em 1996 para 43\% em 2012, muito provavelmente refletindo o aumento do número de municípios, que salta de pouco menos de 5000 em 1996 para mais de 5500 em 2012, e as maiores responsabilidades municipais oriundas na Carta de 1988, ii) o aumento da proporção de servidores na categoria "outros", que passa de cerca de $10 \% \mathrm{em}$ 1996 para cerca de 15\% em 2012, possivelmente refletindo novas formas de gestão pública, e iii) estabilidade na proporção nas outras categorias.

Com relação à escolaridade (Tabela 9), percebemos drástica queda da escolaridade baixa, de 34\% em 1996 para 9\% em 2012, substancial aumento da escolaridade alta, que passa de $21 \%$ em 1996 para $44 \%$ em 2012, e certa estabilidade da escolaridade média, entre 45\% e 50\%. Por fim, no âmbito regional, leve perda de participação do sudeste e sul e suave aumento das outras regiões.

Em suma, i) a totalidade de servidores públicos nesta amostra passa de pouco mais de 7 milhões em 1996 para quase 12 milhões em 2012, ii) parte significativa do emprego está no executivo municipal, e esta proporção aumentou substancialmente nos 16 anos aqui analisados, iii) a participação de servidores de escolaridade baixa caiu drásticamente e a dos servidores de escolaridade alta aumentou substancialmente, iv) há leve desconcentração regional da participação dos servidores públicos.

\section{Conclusões}

Analisamos a evolução e a distribuição por região, escolaridade e natureza jurídica do emprego formal no setor público brasileiro entre 1996 e 2012 a partir dos microdados da Rais trabalhador. Percebemos que há transformações substanciais, como aumento de servidores com escolaridade e redução daqueles com escolaridade baixa, e crescimento notável da participação do emprego 
gerado no executivo municipal. Estes fenônemos mais gerais refletem, cremos, as mundanças instituicionais do Estado brasileiro desde a Constituição de 1988, em particular descentralização e modernização - que exige servidores mais qualificados.

\section{Referências}

Beluzzo, W.; Anuatti-Neto, F.; Pazello, E. T. (2005) Distribuição de salários e diferencias público-privado no Brasil, Revista Brasileira de Economia, v. 59, n. 4, p. 511-533.

Constituição da República Federativa do Brasil de 1988. http://www.planalto.gov.br/ ccivil_03/constituicao/constituicaocompilado.htm Acessado em 09 out 2014.

Ehrenberg, R. G.; Schwarz, J. L. Public-Sector Labor Markets. (1986) In: Ashenfelter, O.; Layard, R. Handbook of Labor Economics. Amsterdan: Elsevier Science Publishers. Volume II, p. 1219-1268.

IPEA. (2009) Políticas Sociais: acompanhamento e análise - Vinte Anos da Constituição Federal. Brasília. Volumes 1,2 e 3.

Lavinas, L. (2013). 21 ${ }^{\text {St }}$ Century Welfare. New Left Review, 84, nov-dec, 2013. PP.5-40 


\section{Anexo 1: Tabelas}

Tabela 1: Total de servidores públicos em cada ano

\begin{tabular}{lc}
\hline ANO & SERVIDORES \\
\hline 1996 & $7.755 .597,50$ \\
1997 & $7.444 .510,50$ \\
1998 & $7.293 .410,00$ \\
1999 & $7.365 .167,50$ \\
2000 & $7.419 .944,00$ \\
2001 & $7.570 .382,00$ \\
2002 & $8.005 .183,50$ \\
2003 & $8.487 .278,50$ \\
2004 & $8.737 .192,00$ \\
2005 & $9.051 .314,50$ \\
2006 & $9.438 .718,00$ \\
2007 & $9.864 .531,50$ \\
2008 & $10.387 .886,00$ \\
2009 & $10.855 .535,00$ \\
2010 & $11.215 .725,00$ \\
2011 & $11.564 .710,00$ \\
2012 & $11.730 .430,50$
\end{tabular}

Fonte: Relação Anual de informações Sociais do Ministério do Trabalho e Emprego (Rais/MTE)

Tabela 2: Distribuição de servidores públicos escolaridade

\begin{tabular}{cc}
\hline Baixa & $17,95 \%$ \\
Media & $47,26 \%$ \\
Alta & $34,80 \%$ \\
\hline Total & $100,00 \%$ \\
\hline
\end{tabular}

Fonte: Relação Anual de informações Sociais do Ministério do Trabalho e Emprego (Rais/MTE)

Tabela 3: Distribuição de servidores públicos por região

\begin{tabular}{cc}
\hline Norte & $6,26 \%$ \\
Nordeste & $21,15 \%$ \\
Sudeste & $46,58 \%$ \\
Sul & $14,86 \%$ \\
Centro Oeste & $11,15 \%$ \\
\hline Total & $100 \%$ \\
\hline
\end{tabular}

Fonte: Relação Anual de informações Sociais do Ministério do Trabalho e Emprego (Rais/MTE) 
Tabela 4: Distribuição de servidores públicos por natureza jurídica

\begin{tabular}{cc}
\hline Executivo Federal & $4,40 \%$ \\
Executivo Estadual & $26,19 \%$ \\
Executivo Municipal & $38,03 \%$ \\
Legislativo Federal & $0,28 \%$ \\
Legislativo Estadual & $0,60 \%$ \\
Legislativo Municipal & $0,82 \%$ \\
Judiciario Federal & $0,83 \%$ \\
Judiciario Estadual & $1,35 \%$ \\
Autarquia Federal & $1,35 \%$ \\
Autarquia Estadual & $2,17 \%$ \\
Autarquia Municipal & $0,99 \%$ \\
Fundacao Federal & $0,54 \%$ \\
Fundacao Estadual & $1,00 \%$ \\
Fundacao Municipal & $0,56 \%$ \\
Empresa Publica & $3,43 \%$ \\
Sociedade Anonima & $4,75 \%$ \\
Outros & $12,51 \%$ \\
\hline Total & $100 \%$ \\
\hline
\end{tabular}

Fonte: Relação Anual de informações Sociais do Ministério do Trabalho e Emprego (Rais/MTE)

Tabela 5: Distribuição de servidores públicos por natureza jurídica e escolaridade

\begin{tabular}{ccccc}
\hline & Baixa & Média & Alta & Total \\
\hline Executivo Federal & $12,25 \%$ & $58,92 \%$ & $28,83 \%$ & $100,00 \%$ \\
Executivo Estadual & $10,06 \%$ & $45,69 \%$ & $44,25 \%$ & $100,00 \%$ \\
Executivo Municipal & $24,39 \%$ & $47,94 \%$ & $27,67 \%$ & $100,00 \%$ \\
Legislativo Federal & $7,41 \%$ & $42,81 \%$ & $49,78 \%$ & $100,00 \%$ \\
Legislativo Estadual & $7,41 \%$ & $53,50 \%$ & $39,10 \%$ & $100,00 \%$ \\
Legislativo Municipal & $18,56 \%$ & $55,45 \%$ & $25,99 \%$ & $100,00 \%$ \\
Judiciario Federal & $1,43 \%$ & $26,05 \%$ & $72,52 \%$ & $100,00 \%$ \\
Judiciario Estadual & $6,21 \%$ & $46,51 \%$ & $47,28 \%$ & $100,00 \%$ \\
Autarquia Federal & $6,14 \%$ & $33,18 \%$ & $60,67 \%$ & $100,00 \%$ \\
Autarquia Estadual & $18,65 \%$ & $38,35 \%$ & $43,01 \%$ & $100,00 \%$ \\
Autarquia Municipal & $29,48 \%$ & $44,42 \%$ & $26,10 \%$ & $100,00 \%$ \\
Fundacao Federal & $17,21 \%$ & $43,31 \%$ & $39,48 \%$ & $100,00 \%$ \\
Fundacao Estadual & $15,66 \%$ & $43,81 \%$ & $40,53 \%$ & $100,00 \%$ \\
Fundacao Municipal & $16,17 \%$ & $47,73 \%$ & $36,10 \%$ & $100,00 \%$ \\
Empresa Publica & $22,68 \%$ & $51,56 \%$ & $25,76 \%$ & $100,00 \%$ \\
Sociedade Anonima & $13,27 \%$ & $44,28 \%$ & $42,45 \%$ & $100,00 \%$ \\
Outros & $18,26 \%$ & $48,93 \%$ & $32,81 \%$ & $100,00 \%$ \\
\hline
\end{tabular}

Fonte: Relação Anual de informações Sociais do Ministério do Trabalho e Emprego (Rais/MTE) 
Tabela 6: Distribuição de servidores públicos por região e natureza jurídica - leitura nas colunas

\begin{tabular}{cccccc}
\hline & NO & NE & SE & SUL & CO \\
\hline Executivo Federal & $4,00 \%$ & $1,53 \%$ & $2,71 \%$ & $1,34 \%$ & $21,20 \%$ \\
Executivo Estadual & $32,89 \%$ & $23,20 \%$ & $27,92 \%$ & $21,64 \%$ & $26,98 \%$ \\
Executivo Municipal & $38,20 \%$ & $50,80 \%$ & $34,39 \%$ & $41,36 \%$ & $24,36 \%$ \\
Legislativo Federal & $0,05 \%$ & $0,01 \%$ & $0,00 \%$ & $0,02 \%$ & $2,45 \%$ \\
Legislativo Estadual & $3,01 \%$ & $0,78 \%$ & $0,30 \%$ & $0,24 \%$ & $0,61 \%$ \\
Legislativo Municipal & $1,05 \%$ & $0,89 \%$ & $0,86 \%$ & $0,79 \%$ & $0,44 \%$ \\
Judiciario Federal & $0,70 \%$ & $0,73 \%$ & $0,64 \%$ & $0,83 \%$ & $1,93 \%$ \\
Judiciario Estadual & $1,57 \%$ & $0,82 \%$ & $1,50 \%$ & $1,95 \%$ & $0,80 \%$ \\
Autarquia Federal & $1,01 \%$ & $1,61 \%$ & $1,08 \%$ & $1,36 \%$ & $2,15 \%$ \\
Autarquia Estadual & $0,77 \%$ & $1,84 \%$ & $2,61 \%$ & $2,62 \%$ & $1,17 \%$ \\
Autarquia Municipal & $0,27 \%$ & $0,65 \%$ & $1,33 \%$ & $1,11 \%$ & $0,42 \%$ \\
Fundacao Federal & $1,07 \%$ & $0,30 \%$ & $0,49 \%$ & $0,25 \%$ & $1,32 \%$ \\
Fundacao Estadual & $0,81 \%$ & $1,32 \%$ & $0,90 \%$ & $0,57 \%$ & $1,55 \%$ \\
Fundacao Municipal & $0,09 \%$ & $0,36 \%$ & $0,78 \%$ & $0,57 \%$ & $0,27 \%$ \\
Empresa Publica & $2,92 \%$ & $2,68 \%$ & $4,30 \%$ & $3,69 \%$ & $2,86 \%$ \\
Sociedade Anonima & $3,30 \%$ & $3,89 \%$ & $5,67 \%$ & $4,91 \%$ & $3,16 \%$ \\
Outros & $8,29 \%$ & $8,59 \%$ & $14,52 \%$ & $16,74 \%$ & $8,33 \%$ \\
\hline Total & $100,00 \%$ & $100,00 \%$ & $100,00 \%$ & $100,00 \%$ & $100,00 \%$ \\
\hline
\end{tabular}

Fonte: Relação Anual de informações Sociais do Ministério do Trabalho e Emprego (Rais/MTE)

Tabela 7: Distribuição de servidores públicos por natureza jurídica e região - leitura nas linhas

\begin{tabular}{ccccccc}
\hline & NO & NE & SE & SUL & CO & TOTAL \\
\hline Executivo Federal & $5,69 \%$ & $7,37 \%$ & $28,62 \%$ & $4,51 \%$ & $53,81 \%$ & $100,00 \%$ \\
Executivo Estadual & $7,86 \%$ & $18,75 \%$ & $49,61 \%$ & $12,27 \%$ & $11,50 \%$ & $100,00 \%$ \\
Executivo Municipal & $6,29 \%$ & $28,28 \%$ & $42,10 \%$ & $16,16 \%$ & $7,15 \%$ & $100,00 \%$ \\
Legislativo Federal & $1,00 \%$ & $0,59 \%$ & $0,50 \%$ & $1,30 \%$ & $96,36 \%$ & $100,00 \%$ \\
Legislativo Estadual & $31,62 \%$ & $27,70 \%$ & $23,13 \%$ & $5,98 \%$ & $11,46 \%$ & $100,00 \%$ \\
Legislativo Municipal & $8,07 \%$ & $22,93 \%$ & $48,69 \%$ & $14,27 \%$ & $5,96 \%$ & $100,00 \%$ \\
Judiciario Federal & $5,29 \%$ & $18,47 \%$ & $35,57 \%$ & $14,79 \%$ & $25,79 \%$ & $100,00 \%$ \\
Judiciario Estadual & $7,26 \%$ & $12,86 \%$ & $51,77 \%$ & $21,47 \%$ & $6,59 \%$ & $100,00 \%$ \\
Autarquia Federal & $4,66 \%$ & $25,25 \%$ & $37,33 \%$ & $14,95 \%$ & $17,76 \%$ & $100,00 \%$ \\
Autarquia Estadual & $2,22 \%$ & $17,90 \%$ & $55,87 \%$ & $17,94 \%$ & $6,04 \%$ & $100,00 \%$ \\
Autarquia Municipal & $1,71 \%$ & $13,94 \%$ & $62,84 \%$ & $16,65 \%$ & $4,79 \%$ & $100,00 \%$ \\
Fundacao Federal & $12,33 \%$ & $11,64 \%$ & $41,78 \%$ & $6,97 \%$ & $27,14 \%$ & $100,00 \%$ \\
Fundacao Estadual & $5,03 \%$ & $27,75 \%$ & $41,52 \%$ & $8,38 \%$ & $17,25 \%$ & $100,00 \%$ \\
Fundacao Municipal & $1,04 \%$ & $13,56 \%$ & $64,92 \%$ & $15,06 \%$ & $5,27 \%$ & $100,00 \%$ \\
Empresa Publica & $5,05 \%$ & $15,67 \%$ & $55,28 \%$ & $15,12 \%$ & $8,80 \%$ & $100,00 \%$ \\
Sociedade Anonima & $4,35 \%$ & $17,34 \%$ & $55,49 \%$ & $15,36 \%$ & $7,43 \%$ & $100,00 \%$ \\
Outros & $4,15 \%$ & $14,52 \%$ & $54,01 \%$ & $19,88 \%$ & $7,44 \%$ & $100,00 \%$ \\
\hline
\end{tabular}

Fonte: Relação Anual de informações Sociais do Ministério do Trabalho e Emprego (Rais/MTE) 


\begin{tabular}{|c|c|c|c|c|c|c|c|c|c|c|c|c|c|c|c|c|c|c|}
\hline 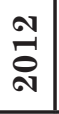 & $\begin{array}{l}\partial^{0} \\
\dot{b} \\
\infty \\
\infty\end{array}$ & $\begin{array}{l}\text { ఏ̊ } \\
\text { 尺 } \\
\text { ลิ }\end{array}$ & $\begin{array}{l}\text { oे } \\
\text { oे } \\
\text { oิ }\end{array}$ & 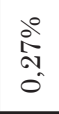 & 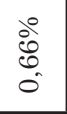 & $\begin{array}{c}0 \\
0 \\
0 \\
0 \\
0\end{array}$ & $\underset{\stackrel{\circ}{\circ}}{\stackrel{0}{\circ}}$ & $\begin{array}{l}\text { वें } \\
\text { जे } \\
-1\end{array}$ & $\begin{array}{l}\stackrel{0}{0} \\
0 \\
- \\
-\end{array}$ & $\begin{array}{l}\stackrel{\circ}{\circ} \\
\vec{g} \\
\rightarrow\end{array}$ & $\begin{array}{l}\stackrel{े}{\circ} \\
\text { के } \\
0\end{array}$ & \begin{tabular}{l}
$\stackrel{\circ}{\circ}$ \\
\multirow{z}{*}{} \\
0
\end{tabular} & 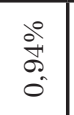 & $\begin{array}{l}80 \\
8 \\
0 \\
0\end{array}$ & 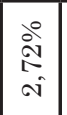 & 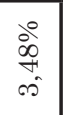 & $\begin{array}{l}\stackrel{0}{\circ}^{\circ} \\
\dot{\vec{b}} \\
\stackrel{+}{+}\end{array}$ & $\begin{array}{l}8 \\
8 \\
8\end{array}$ \\
\hline 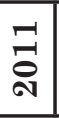 & $\begin{array}{l}\stackrel{0}{0} \\
\dot{0} \\
\infty\end{array}$ & $\begin{array}{l}\text { 今े } \\
\text { ले } \\
\text { ô }\end{array}$ & 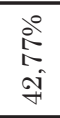 & 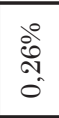 & $\begin{array}{l}D^{\circ} \\
\infty \\
0 \\
0 \\
0\end{array}$ & $\begin{array}{c}0 \\
\stackrel{0}{\circ} \\
\circ \\
\circ\end{array}$ & $\begin{array}{l}i^{\circ} \\
10 \\
0 \\
0 \\
0\end{array}$ & $\begin{array}{l}\stackrel{\circ}{\circ} \\
\stackrel{-}{-}\end{array}$ & $\begin{array}{l}\text { 今े } \\
\text { : } \\
-i\end{array}$ & 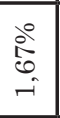 & $\begin{array}{l}\stackrel{0}{\infty} \\
\infty \\
0 \\
0\end{array}$ & 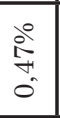 & $\begin{array}{l}0 \\
0 \\
0 \\
10 \\
0 \\
0\end{array}$ & $\begin{array}{l}\text { 吕 } \\
\text { : } \\
0 \\
0 \\
0\end{array}$ & 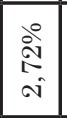 & $\begin{array}{l}\text { के } \\
\infty \\
\infty \\
\infty^{0}\end{array}$ & 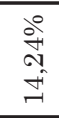 & $\begin{array}{l}0 \\
8 \\
8 \\
8 \\
8 \\
\end{array}$ \\
\hline 웅 & $\begin{array}{l}\stackrel{\circ}{\circ} \\
\stackrel{0}{c} \\
\infty\end{array}$ & $\begin{array}{l}\text { io } \\
\text { in } \\
\text { is } \\
\text { o }\end{array}$ & 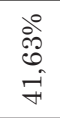 & $\begin{array}{l}\text { ¿ें } \\
\stackrel{\circ}{0} \\
o 1\end{array}$ & 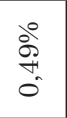 & $\mid \begin{array}{l}0 \\
\stackrel{0}{+} \\
0 \\
0\end{array}$ & $\begin{array}{l}\text { वे } \\
\overbrace{}^{\circ} \\
0^{\circ}\end{array}$ & $\begin{array}{l}\stackrel{\circ}{\circ} \\
\stackrel{0}{-}\end{array}$ & $\begin{array}{l}\stackrel{\circ}{\circ} \\
\stackrel{9}{9} \\
\rightarrow\end{array}$ & 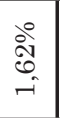 & $\begin{array}{l}\text { के } \\
\text { के } \\
0\end{array}$ & $\begin{array}{c}\text { के } \\
\text { iे } \\
\text { : } \\
0\end{array}$ & 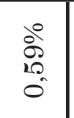 & $\begin{array}{l}80 \\
8 \\
0 \\
0 \\
0\end{array}$ & 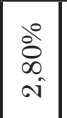 & 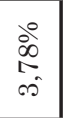 & $\begin{array}{l}\stackrel{0}{\circ} \\
\infty \\
\infty \\
\stackrel{\infty}{\sim}\end{array}$ & $\begin{array}{l}\text { oे } \\
8 \\
8 \\
8 \\
0\end{array}$ \\
\hline 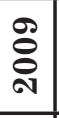 & 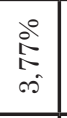 & 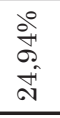 & $\begin{array}{l}\text { oे } \\
\text { ô } \\
\text { of } \\
\text { f }\end{array}$ & 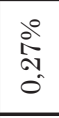 & $\begin{array}{l}\text { 离 } \\
\text { iे } \\
0^{\circ} \\
\end{array}$ & \begin{tabular}{|c|}
0 \\
i \\
10 \\
0 \\
0 \\
\end{tabular} & $\begin{array}{l}\dot{0}^{\circ} \\
\dot{\infty}^{0} \\
0^{\prime}\end{array}$ & $\begin{array}{l}\stackrel{2}{\circ} \\
\stackrel{2}{=}\end{array}$ & 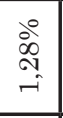 & $\begin{array}{l}\stackrel{\circ}{\circ} \\
\vec{b} \\
\dot{-}\end{array}$ & 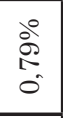 & $\begin{array}{c}\text { oे } \\
\text { iे } \\
\text { i. } \\
0^{\circ}\end{array}$ & $\begin{array}{l}\dot{0}^{\circ} \\
\vdots \\
0 \\
0\end{array}$ & 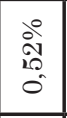 & 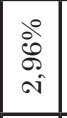 & $\begin{array}{l}\text { 吕 } \\
\stackrel{1}{\circ} \\
\infty \\
\infty^{2}\end{array}$ & 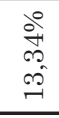 & 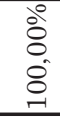 \\
\hline $\begin{array}{l}\infty \\
\stackrel{\infty}{\circ} \\
\stackrel{్}{\circ}\end{array}$ & 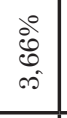 & 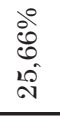 & 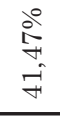 & $\begin{array}{l}\circ \\
\stackrel{0}{0} \\
\tilde{\sigma}_{0} \\
0\end{array}$ & $\begin{array}{l}{ }^{\circ} \\
\text { o. } \\
0 \\
0\end{array}$ & $\begin{array}{c}0 \\
\stackrel{0}{0} \\
\infty \\
\infty \\
0 \\
\end{array}$ & $\begin{array}{l}\partial_{0}^{\circ} \\
\dot{\infty} \\
0^{\circ}\end{array}$ & 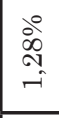 & $\begin{array}{l}\stackrel{\circ}{+} \\
\stackrel{H}{H} \\
\rightarrow\end{array}$ & $\begin{array}{l}\stackrel{0}{\circ} \\
\text { i̊ } \\
\stackrel{-}{-}\end{array}$ & $\begin{array}{c}0 \\
\text { aे } \\
\infty \\
\infty \\
0 \\
\end{array}$ & $\begin{array}{c}0 \\
8 \\
0 \\
0 \\
0 \\
0\end{array}$ & $\begin{array}{l}0 \\
0 \\
0 \\
0 \\
0\end{array}$ & \begin{tabular}{|c|}
20 \\
$\dot{0}$ \\
0 \\
0 \\
\end{tabular} & 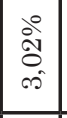 & $\begin{array}{l}\text { के } \\
\infty \\
\infty \\
\infty \\
\end{array}$ & 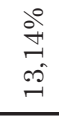 & $\begin{array}{l}\text { ठें } \\
\text { 8े } \\
\text { वे }\end{array}$ \\
\hline 於 & 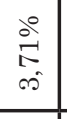 & 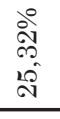 & $\begin{array}{l}\stackrel{\circ}{\circ} \\
\stackrel{5}{+} \\
\vec{F}\end{array}$ & 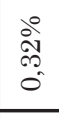 & 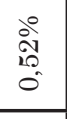 & 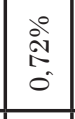 & $\begin{array}{l}\text { के } \\
\text { oे } \\
\infty \\
0 \\
\end{array}$ & 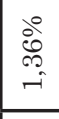 & \begin{tabular}{l}
$\stackrel{\circ}{+}$ \\
\multirow{H}{H}{} \\
$\rightarrow$
\end{tabular} & $\begin{array}{l}0 \\
\dot{0} \\
\circ \\
\circ\end{array}$ & $\begin{array}{l}\dot{0} \\
\dot{+} \\
0 \\
0 \\
\end{array}$ & 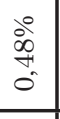 & $\begin{array}{l}\text { बें } \\
\text { oे } \\
0 \\
0\end{array}$ & 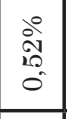 & \begin{tabular}{|l|}
0 \\
$\overrightarrow{7}$ \\
$\infty$ \\
\end{tabular} & $\begin{array}{l}\infty \\
\infty \\
\infty \\
\infty\end{array}$ & 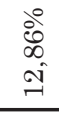 & $\begin{array}{l}\text { 8ें } \\
8 \\
8 \\
0\end{array}$ \\
\hline ஜ̊̊ి & 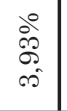 & 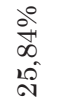 & 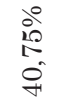 & 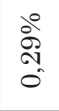 & 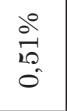 & 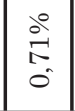 & 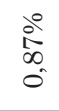 & $\begin{array}{l}\stackrel{0}{0} \\
\stackrel{0}{\circ} \\
\stackrel{-}{-}\end{array}$ & $\begin{array}{l}\stackrel{0}{\circ} \\
\stackrel{\leftrightarrow}{-} \\
-1\end{array}$ & 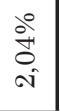 & $\begin{array}{l}\dot{0} \\
\dot{0} \\
0 \\
0\end{array}$ & $\begin{array}{c}\text { 究 } \\
\text { in } \\
0\end{array}$ & $\begin{array}{l}\delta^{\circ} \\
\delta_{0} \\
0^{\circ}\end{array}$ & $\begin{array}{l}\stackrel{0}{0} \\
\infty \\
10 \\
0\end{array}$ & 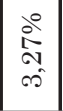 & 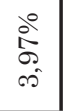 & 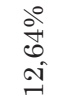 & $\begin{array}{l}\text { ठें } \\
\text { 8े } \\
8\end{array}$ \\
\hline 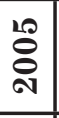 & $\begin{array}{l}\stackrel{\circ}{\circ} \\
\stackrel{+}{+} \\
\stackrel{+}{*}\end{array}$ & $\begin{array}{l}\text { oे } \\
\text { I } \\
\text { ô } \\
\text { ô }\end{array}$ & $\begin{array}{l}\text { बें } \\
\text { oे } \\
\text { ○े } \\
\end{array}$ & 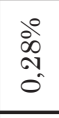 & 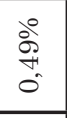 & $\begin{array}{l}\dot{0}^{\circ} \\
\dot{0} \\
0^{\circ}\end{array}$ & 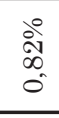 & 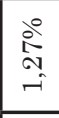 & $\begin{array}{l}\text { वे } \\
\stackrel{9}{9} \\
\stackrel{-1}{-1} \\
\end{array}$ & 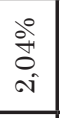 & 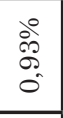 & 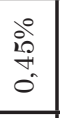 & $\begin{array}{l}\text { jo } \\
\vdots \\
0 \\
0\end{array}$ & \begin{tabular}{|l|}
8 \\
10 \\
10 \\
0 \\
\end{tabular} & 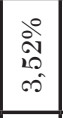 & $\begin{array}{l}\stackrel{\circ}{0} \\
\ddot{\leftrightarrow} \\
+ \\
\end{array}$ & 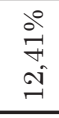 & $\begin{array}{l}\text { oे } \\
8 \\
8 \\
8 \\
\end{array}$ \\
\hline 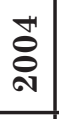 & 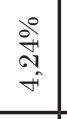 & 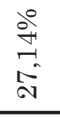 & 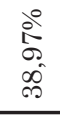 & 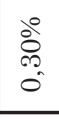 & $\begin{array}{l}0 \\
0 \\
0 \\
0 \\
0 \\
\end{array}$ & $\begin{array}{l}0 \\
\infty^{\circ} \\
0_{0} \\
0^{\circ}\end{array}$ & $\begin{array}{l}\text { के } \\
\text { के } \\
0\end{array}$ & 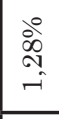 & $\begin{array}{l}\text { 今े } \\
\text { Ǹ } \\
\rightarrow\end{array}$ & $\begin{array}{l}0 \\
\infty^{\circ} \\
0 \\
0 \\
\text { o } \\
\end{array}$ & $\begin{array}{c}\circ \\
\stackrel{0}{\circ} \\
\stackrel{8}{9} \\
0 \\
\end{array}$ & $\begin{array}{c}\circ \\
\stackrel{0}{\circ} \\
\dot{20} \\
0 \\
\end{array}$ & 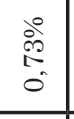 & \begin{tabular}{|c|}
20 \\
10 \\
10 \\
0 \\
0
\end{tabular} & \begin{tabular}{|c|} 
\\
0 \\
0 \\
$\infty$ \\
\end{tabular} & $\begin{array}{l}\stackrel{\circ}{2} \\
\stackrel{1}{7} \\
\stackrel{+}{+} \\
\end{array}$ & $\begin{array}{l}\text { 今े } \\
\text { N. } \\
\text { जิ } \\
\end{array}$ & $\begin{array}{l}\text { ठें } \\
8 \\
8 \\
0\end{array}$ \\
\hline ஜ̊. & $\begin{array}{c}\stackrel{\circ}{\circ} \\
\stackrel{0}{0} \\
\stackrel{\leftrightarrow}{+} \\
\end{array}$ & 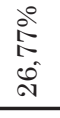 & 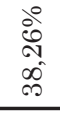 & $\begin{array}{l}0 \\
\vdots \\
0 \\
0 \\
0\end{array}$ & 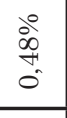 & $\begin{array}{l}0 \\
\stackrel{0}{0} \\
0 \\
0^{-}\end{array}$ & $\begin{array}{l}\text { aे } \\
\stackrel{0}{\circ} \\
0 \\
\end{array}$ & 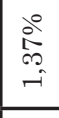 & $\begin{array}{l}\stackrel{\circ}{\circ} \\
\stackrel{-}{-}\end{array}$ & 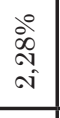 & $\begin{array}{l}\stackrel{\circ}{0} \\
\dot{\mathrm{i}} \\
\end{array}$ & $\begin{array}{l}0 \\
\vdots \\
0 \\
0 \\
0 \\
0 \\
\end{array}$ & $\stackrel{\text { 今े }}{\stackrel{-}{-}}$ & 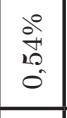 & \begin{tabular}{|c|}
0 \\
0 \\
$\infty$ \\
$\infty$ \\
$\infty^{\circ}$ \\
\end{tabular} & $\begin{array}{l}\stackrel{\circ}{\circ} \\
\stackrel{\leftrightarrow}{+} \\
\end{array}$ & 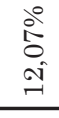 & $\begin{array}{l}\dot{8}^{\circ} \\
8 \\
8 \\
\end{array}$ \\
\hline 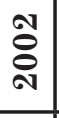 & $\begin{array}{l}\stackrel{\circ}{\circ} \\
\vec{\leftrightarrow} \\
\dot{\leftrightarrow}^{+} \\
\end{array}$ & 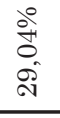 & $\begin{array}{l}\stackrel{0}{\circ} \\
\stackrel{3}{-} \\
\stackrel{5}{\circ} \\
\end{array}$ & $\begin{array}{l}0 \\
\vdots \\
0 \\
0 \\
0\end{array}$ & $\begin{array}{l}0 \\
\stackrel{0}{2} \\
\text { th } \\
0 \\
\end{array}$ & $\begin{array}{l}\stackrel{\circ}{\circ} \\
\stackrel{\mathrm{N}}{\mathrm{O}} \\
0\end{array}$ & $\begin{array}{l}\text { o } \\
\text { is } \\
0 \\
0 \\
0\end{array}$ & 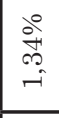 & 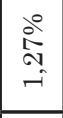 & 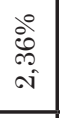 & $\underset{\mathrm{\Xi}}{\circ}$ & $\begin{array}{l}\text { ¿ें } \\
\text { రे. } \\
0 \\
0\end{array}$ & $\begin{array}{l}\text { oे } \\
\stackrel{-}{-} \\
-\end{array}$ & 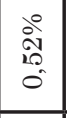 & \begin{tabular}{l|}
$\stackrel{\circ}{\circ}$ \\
$\vec{F}$ \\
\multirow{+}{*}{}
\end{tabular} & $\begin{array}{l}\stackrel{\circ}{\circ} \\
\stackrel{+}{+} \\
\rightarrow \\
\end{array}$ & $\begin{array}{l}\circ \\
\stackrel{\circ}{\circ} \\
\omega^{\circ}\end{array}$ & $\begin{array}{l}\text { ठें } \\
8 \\
8 \\
0\end{array}$ \\
\hline ర্் & 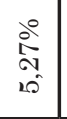 & $\begin{array}{l}\text { वे } \\
\text { के } \\
\text { बें }\end{array}$ & $\begin{array}{l}\circ \\
\infty \\
\infty \\
10 \\
10 \\
\infty\end{array}$ & $\begin{array}{l}\text { @े } \\
\stackrel{0}{\infty} \\
0\end{array}$ & \begin{tabular}{l}
$\infty$ \\
$\infty$ \\
$\infty$ \\
\multirow{0}{*}{} \\
0
\end{tabular} & $\begin{array}{l}\stackrel{0}{\circ} \\
\stackrel{10}{\circ} \\
0 \\
0\end{array}$ & $\begin{array}{l}\partial^{\circ} \\
\sigma_{0} \\
0\end{array}$ & 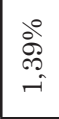 & $\begin{array}{l}\stackrel{0}{0} \\
\dot{0} \\
- \\
-1 \\
-1\end{array}$ & $\begin{array}{l}\circ \\
\dot{0} \\
\dot{0} \\
\circ\end{array}$ & $\begin{array}{l}\stackrel{\circ}{\circ} \\
\stackrel{0}{-} \\
-1\end{array}$ & $\begin{array}{l}\text { ०ें } \\
\text { லें } \\
0\end{array}$ & $\begin{array}{l}{ }_{0}^{\circ} \\
\infty \\
-1 \\
-1\end{array}$ & $\begin{array}{l}0 \\
0 \\
010 \\
0 \\
0\end{array}$ & \begin{tabular}{|c|}
0 \\
8 \\
0 \\
$\infty^{\circ}$
\end{tabular} & $\begin{array}{c}\stackrel{\circ}{\stackrel{+}{+}} \\
\stackrel{+}{+}\end{array}$ & $\begin{array}{l}\text { ठे } \\
\text { ठ } \\
\Rightarrow\end{array}$ & $\begin{array}{l}\dot{0} \\
\dot{8} \\
8 \\
8\end{array}$ \\
\hline 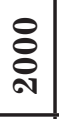 & $\begin{array}{l}\circ 0 \\
\stackrel{0}{\infty} \\
10 \\
10\end{array}$ & 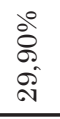 & $\begin{array}{l}\circ \\
\infty \\
\infty \\
\infty \\
\infty \\
\infty \\
\infty\end{array}$ & $\begin{array}{l}\text { वे } \\
\stackrel{0}{0} \\
0 \\
0\end{array}$ & $\begin{array}{l}\infty \\
\infty \\
2 \\
0 \\
0\end{array}$ & $\begin{array}{l}\text { 今े } \\
\text { ठ. } \\
0\end{array}$ & $\begin{array}{l}0^{\circ} \\
\infty \\
\infty \\
0 \\
0\end{array}$ & 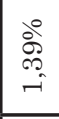 & \begin{tabular}{|cc}
$\stackrel{0}{\circ}$ \\
$\stackrel{\leftrightarrow}{+}$ \\
- \\
\end{tabular} & $\begin{array}{l}\text { वे } \\
\text { iे } \\
\text { o } \\
\text { o }\end{array}$ & 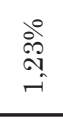 & $\begin{array}{l}0 \\
18 \\
0 \\
0 \\
0\end{array}$ & 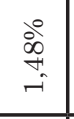 & $\begin{array}{l}0 \\
4 \\
10 \\
0 \\
0\end{array}$ & 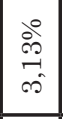 & $\begin{array}{l}\stackrel{0}{ } \\
\triangleright \\
\stackrel{+}{+} \\
\end{array}$ & $\begin{array}{l}\dot{O}^{\circ} \\
\stackrel{0}{\circ} \\
\exists \\
\end{array}$ & $\underset{-1}{8}$ \\
\hline$\underset{\mathscr{I}}{\mathscr{g}}$ & $\begin{array}{l}0 \\
\infty \\
0 \\
10^{\circ} \\
\end{array}$ & 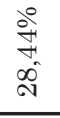 & 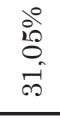 & $\begin{array}{l}\circ \\
\stackrel{े}{\circ} \\
\stackrel{5}{\circ} \\
\end{array}$ & $\begin{array}{l}\stackrel{0}{\circ} \\
\stackrel{10}{0} \\
0\end{array}$ & $\begin{array}{l}\stackrel{0}{\circ} \\
\stackrel{0}{\circ} \\
\stackrel{-}{-}\end{array}$ & $\begin{array}{l}0 \\
\stackrel{0}{0} \\
\infty \\
0 \\
0\end{array}$ & 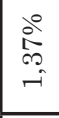 & 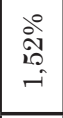 & 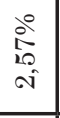 & 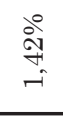 & $\begin{array}{l}\circ \\
\stackrel{0}{0} \\
\dot{0}\end{array}$ & 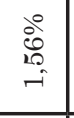 & $\begin{array}{l}\text { Oें } \\
0 \\
0 \\
0\end{array}$ & \begin{tabular}{|c|} 
\\
\\
$\infty$ \\
$\infty$ \\
$\infty^{\circ}$ \\
\end{tabular} & 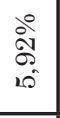 & $\begin{array}{l}\text { ì } \\
\text { in } \\
\text { जे } \\
\text { ปे }\end{array}$ & $\begin{array}{l}\text { ठें } \\
8 \\
8 \\
8\end{array}$ \\
\hline $\begin{array}{l}\infty \\
\stackrel{2}{\curvearrowright} \\
\stackrel{\sim}{2}\end{array}$ & $\begin{array}{l}\circ \\
8 \\
0 \\
0\end{array}$ & $\begin{array}{l}\text { ठे } \\
\text { 今. } \\
\text { ลे } \\
\end{array}$ & 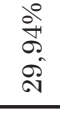 & $\begin{array}{l}\text { o } \\
\text { in } \\
\text { in } \\
0 \\
\end{array}$ & $\begin{array}{l}0^{\circ} \\
\dot{0} \\
0 \\
0\end{array}$ & $\begin{array}{l}\circ \\
\text { ฟे }\end{array}$ & $\begin{array}{l}\text { oे } \\
\text { के } \\
0 \\
0\end{array}$ & 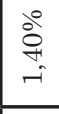 & 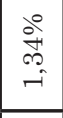 & 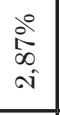 & $\begin{array}{l}\stackrel{\circ}{\circ} \\
\stackrel{1}{2} \\
\stackrel{-}{-}\end{array}$ & $\begin{array}{l}0 \\
\stackrel{0}{0} \\
0 \\
0 \\
0\end{array}$ & 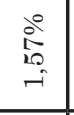 & $\begin{array}{l}80 \\
0 \\
0 \\
0\end{array}$ & \begin{tabular}{|l|} 
\\
$\stackrel{0}{0}$ \\
$\infty$ \\
+ \\
+
\end{tabular} & \begin{tabular}{l}
0 \\
$\vdots$ \\
\multirow{2}{0}{} \\
0 \\
0 \\
0 \\
\end{tabular} & $\begin{array}{l}\text { के } \\
\stackrel{8}{\circ} \\
ت\end{array}$ & $\begin{array}{l}8 \\
8 \\
8 \\
8\end{array}$ \\
\hline$\stackrel{\mathfrak{\sigma}}{\mathscr{\sigma}}$ & $\begin{array}{l}\stackrel{0}{0} \\
10\end{array}$ & $\begin{array}{l}d^{\circ} \\
\text { ర్ } \\
\text { 今 }\end{array}$ & $\begin{array}{l}\stackrel{\circ}{\circ} \\
\sigma_{\sigma} \\
\stackrel{\circ}{\circ}\end{array}$ & $\begin{array}{l}\text { ஃे } \\
\text { ô } \\
\text { ô }\end{array}$ & $\begin{array}{l}\overbrace{}^{\circ} \\
\infty_{0}^{0} \\
0 \\
0\end{array}$ & $\begin{array}{l}\stackrel{\circ}{\circ} \\
\stackrel{-}{=}\end{array}$ & $\begin{array}{l}\dot{0}^{\circ} \\
\dot{\infty}_{0} \\
0^{-}\end{array}$ & 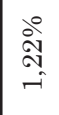 & $\begin{array}{l}\stackrel{\circ}{\circ} \\
\stackrel{-}{-} \\
-7\end{array}$ & $\begin{array}{l}\text { वे } \\
\text { के } \\
\omega^{2}\end{array}$ & $\begin{array}{l}\stackrel{0}{\circ} \\
\stackrel{\vec{m}}{\rightarrow}\end{array}$ & $\begin{array}{l}\circ \\
\vec{b} \\
\dot{0} \\
\dot{0}\end{array}$ & $\begin{array}{l}\stackrel{0}{\circ} \\
\stackrel{5}{5} \\
-i\end{array}$ & $\begin{array}{l}\therefore \\
\dot{0} \\
0 \\
0\end{array}$ & $\begin{array}{l}\stackrel{0}{\circ} \\
i 0 \\
\stackrel{+}{+}\end{array}$ & $\begin{array}{l}\dot{0} \\
\dot{0} \\
\dot{\sigma}^{2}\end{array}$ & 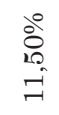 & $\begin{array}{l}0 \\
8 \\
8 \\
8 \\
8\end{array}$ \\
\hline 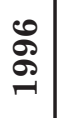 & 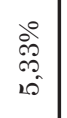 & 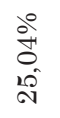 & 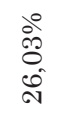 & $\begin{array}{l}\text { ì } \\
\text { in } \\
\text { o. }\end{array}$ & $\begin{array}{l}\text { 今े } \\
\text { o. } \\
0_{0}^{\circ}\end{array}$ & $\begin{array}{c}\stackrel{0}{\circ} \\
\text { dे } \\
\vec{i}\end{array}$ & $\begin{array}{l}\partial^{\circ} \\
0 \\
0 \\
0\end{array}$ & 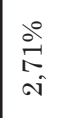 & 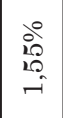 & 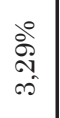 & \begin{tabular}{l}
$\stackrel{\circ}{\circ}$ \\
\multirow{\lambda}{*}{} \\
-1
\end{tabular} & $\begin{array}{l}0 \\
\stackrel{0}{0} \\
0 \\
0\end{array}$ & 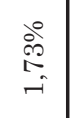 & 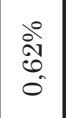 & $\begin{array}{l}\stackrel{\circ}{0} \\
\infty \\
\dot{0}\end{array}$ & $\begin{array}{l}\stackrel{0}{0} \\
\sigma^{2} \\
\sigma^{2}\end{array}$ & $\begin{array}{l}\partial^{\circ} \\
\sigma_{0}^{\circ} \\
\sigma_{0}\end{array}$ & $\begin{array}{l}0 \\
8 \\
8 \\
8 \\
0 \\
0\end{array}$ \\
\hline & 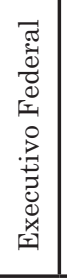 & 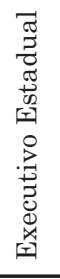 & 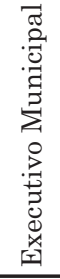 & 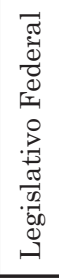 & 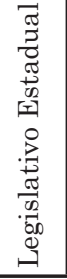 & 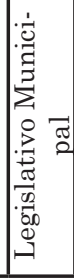 & 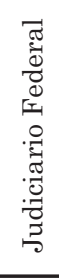 & 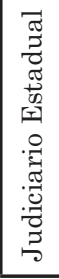 & 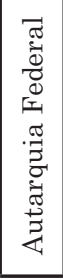 & 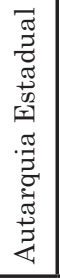 & 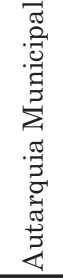 & 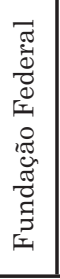 & 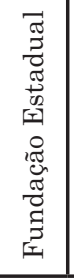 & 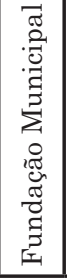 & 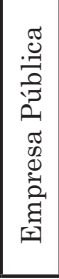 & 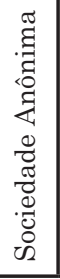 & 总 & 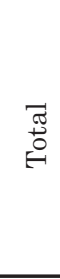 \\
\hline
\end{tabular}




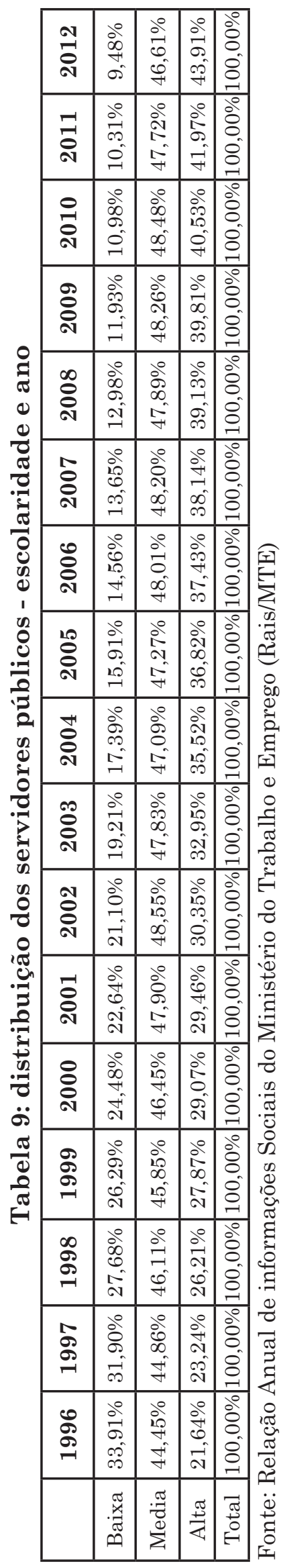




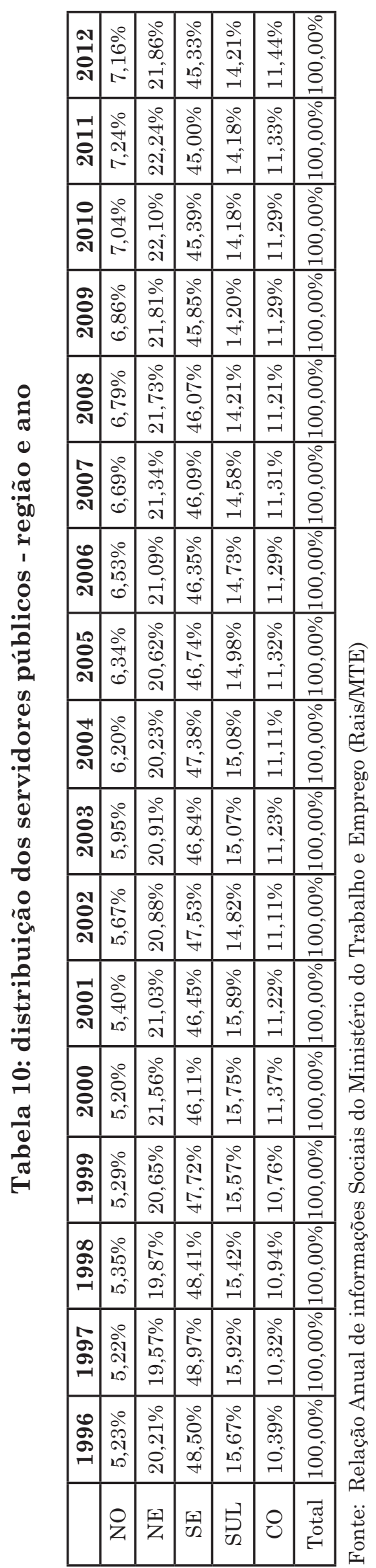

